\title{
Hvordan forhindrer jeg brugere i atforetage indsendelser via hjemmeside til vores tidsskrift?
}

\section{Opdateret til OJS $3.2^{i}$}

Gælder alle brugere inklusiv tidligere registrerede forfattere, dog ikke redakt $\varnothing$ rer eller sektionsredakt $\varnothing$ rer

Hvis du ønsker, at det kun skal være redaktionsmedlemmer, der kan foretage indsendelser til jeres tidsskrift, skal du foretage følgende tilretninger:

1. Under 'Indstillinger' > 'Website' > 'Opsætning' - 'Side-menu' skal du sikre dig, at der ikke er indsat et flueben ud for "Indsend" (blok).

Måske optræder dette element slet ikke i din menuoversigt. I så fald er det ikke blevet aktiveret under 'Plugins' og du kan se bort fra dette punkt.

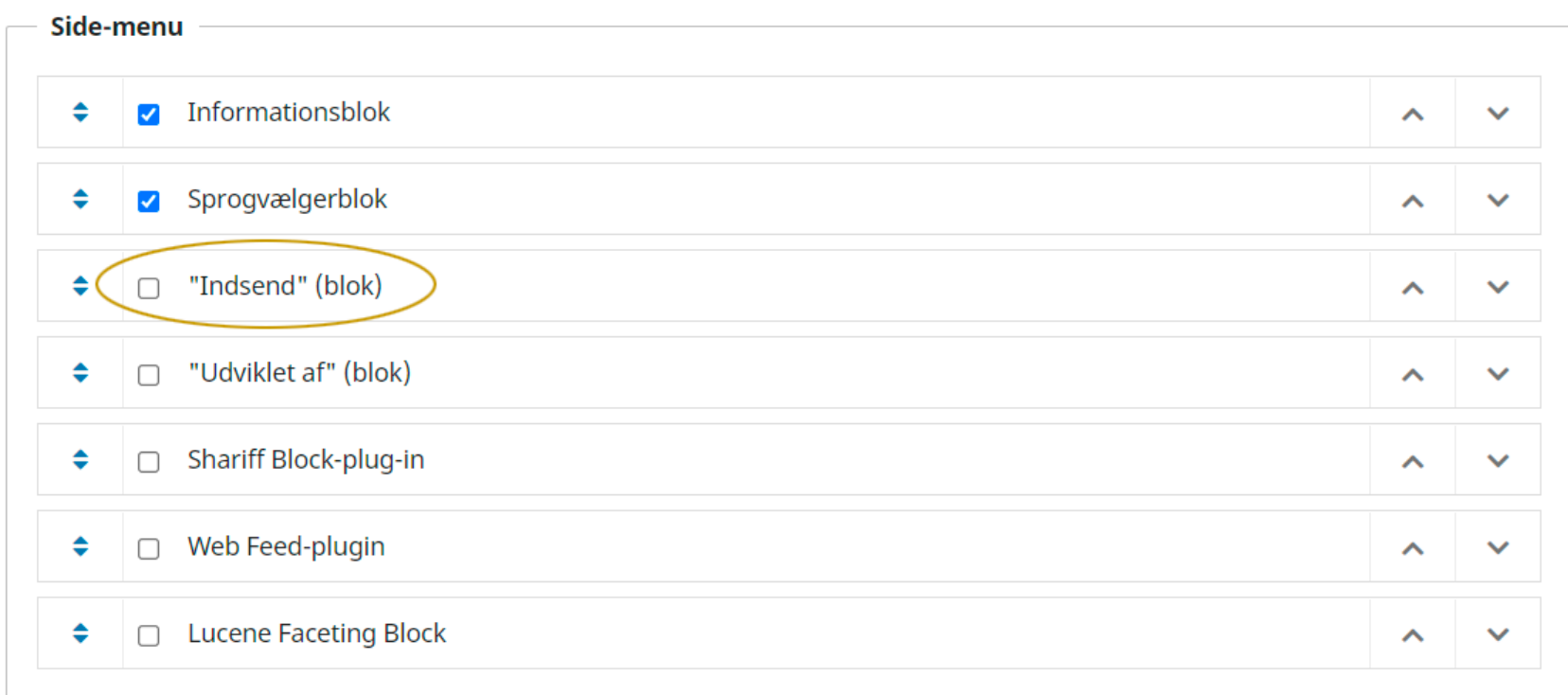


2. Linket 'Indsendelser' skal slettes fra Om-menuen. Det gøres ved, at du går ind under 'Indstillinger' > 'Website' > Opsætning' > 'Navigation'. Her klikker du på den lille blå trekant ud for 'Primary Navigation Menu'. Efterfølgende vælger du linket 'Redigér'

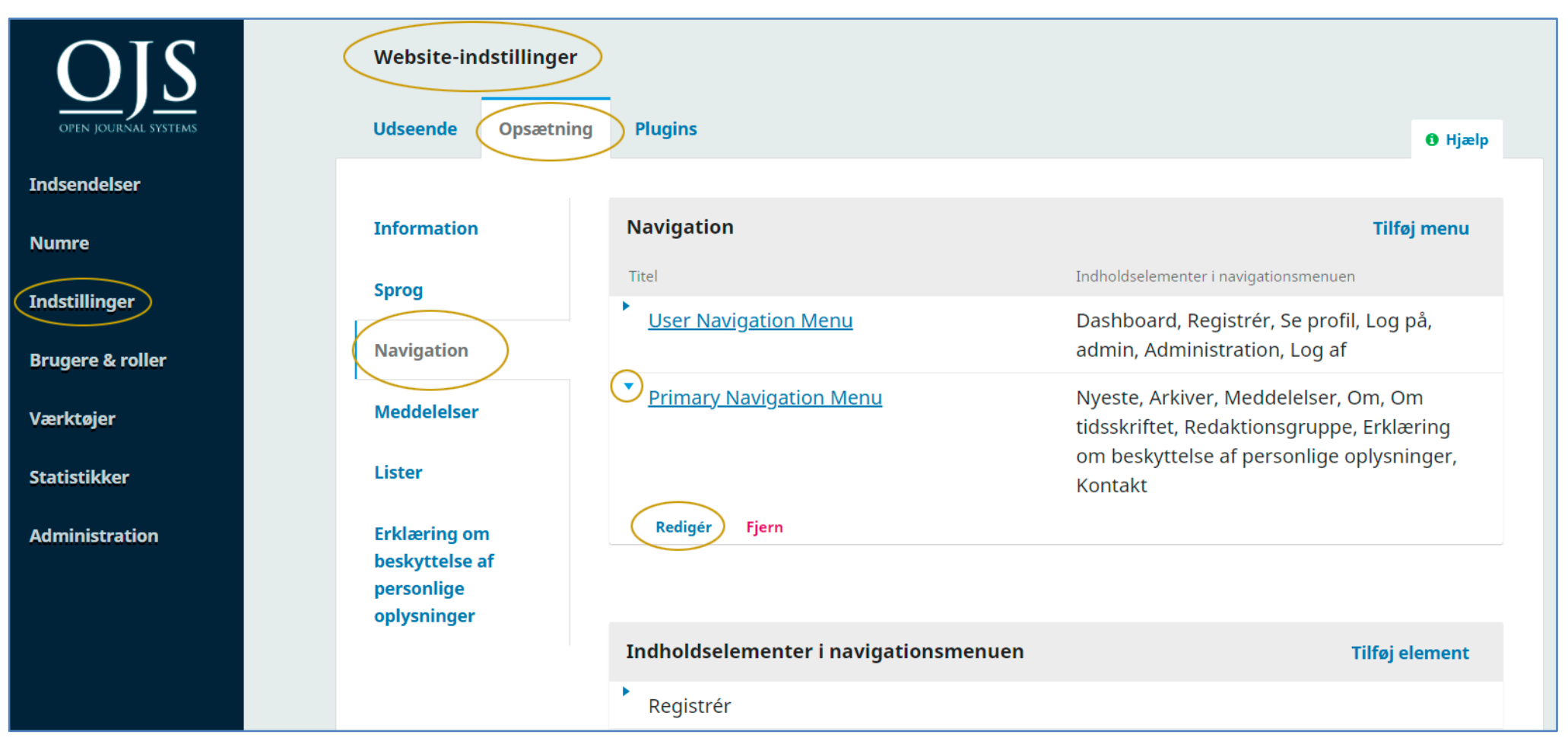


I det vindue, der kommer frem, skal du sørge for at elementet 'Indsendelser' flyttes fra kolonnen 'Tildelte menuelementer' til 'Annullerede menuelementer'. Sæt curseren over op-ned-pilene og hold venstre museknap nede.

$$
\text { ôtm Indsendelser }
$$

Herefter kan elementet føres over i den højre kolonne. Husk efterfølgende at klikke på knappen 'Gem' nederst på siden (ikke med på billedet).
Titel *

Primary Navigation Menu

Aktive tema-navigationsområder

primary

Weelg et navigationsomre̊de

\begin{tabular}{|l|l}
\hline Tildelte menuelementer & Annulerede menuelementer \\
\hline
\end{tabular}

- Nyeste

- Arkiver

Meddelelser

- Registrér

Om

$\mathbf{A}$

- Om tidsskriftet

- Redaktionsgrupp

- Se profil

- Erklæring om beskyttelse af personlige oplysninger

- Kontakt

क
- Administration

togat

- Log af

Indsendelser 
3. Med fjernelsen af siden 'Indsendelser' vil den tekst, der eventuelt er skrevet ind i feltet 'Retningslinjer for forfattere' også forsvinde. Ønsker du, at der skal være adgang til en forfattervejledning på hjemmesiden, skal du derfor nu oprette en side under navigationsmenuen. Dette gøres på følgende måde:

På navigationssiden vælges linket 'Tilføj element'

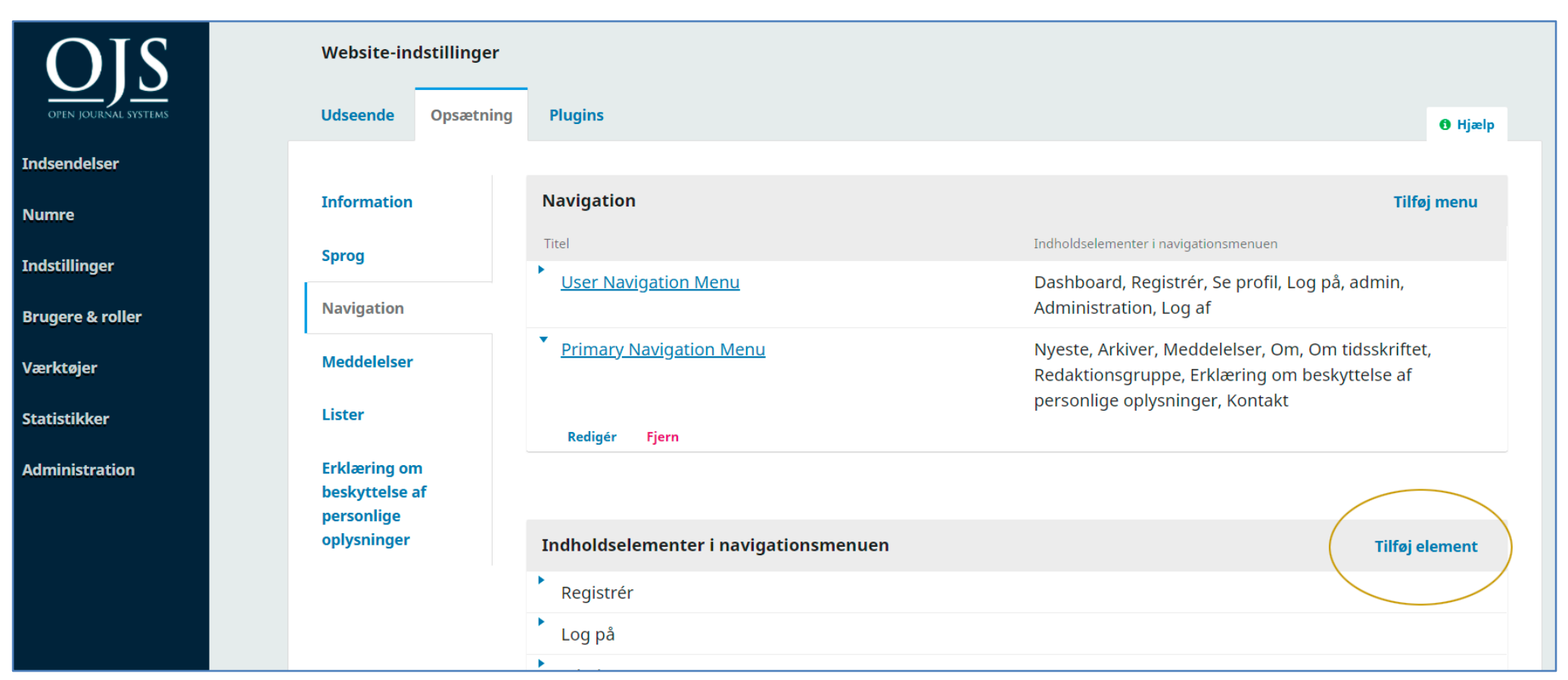


I pop-up-vinduet udfyldes de relevante felter:

1. Vælg titel (her 'Retningslinjer for forfattere').

2. Vælg 'Brugerdefineret side' $\mathrm{i}$ dropdown-menuen

3. Tilføj afsluttende URL-sti

4. Indskriv din forfattervejledning $\mathrm{i}$ feltet 'Indhold' og klik på 'Gem'

\section{Titel *}

Retningslinjer for forfattere

2)

Opret en brugerdefineret side på dit websted og link til den fra navigationsmenuen.

Brugerdefineret side

Opret en orugerdefineret side på dit websted og link til den fra navigationsmenuen.

3)

Sti *

forfat

Denne side vil være tilgængelig på:

https://tidsskrift.dk/ifra/\%PATH\%

...hvor \% PATH\% er stien, der indskrives ovenfor. Bemærk: To sider kan ikke have samme sti. Hvis man anvender stier, der allerede er en del af systemet kan man miste adgang til vigtige funktioner.

4)

Indhold

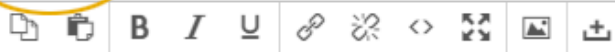


For at få lagt den nye side ind under 'Om', klikker du igen på den lille blå trekant ud for 'Primary Navigation Menu' og vælger linket 'Redigér'

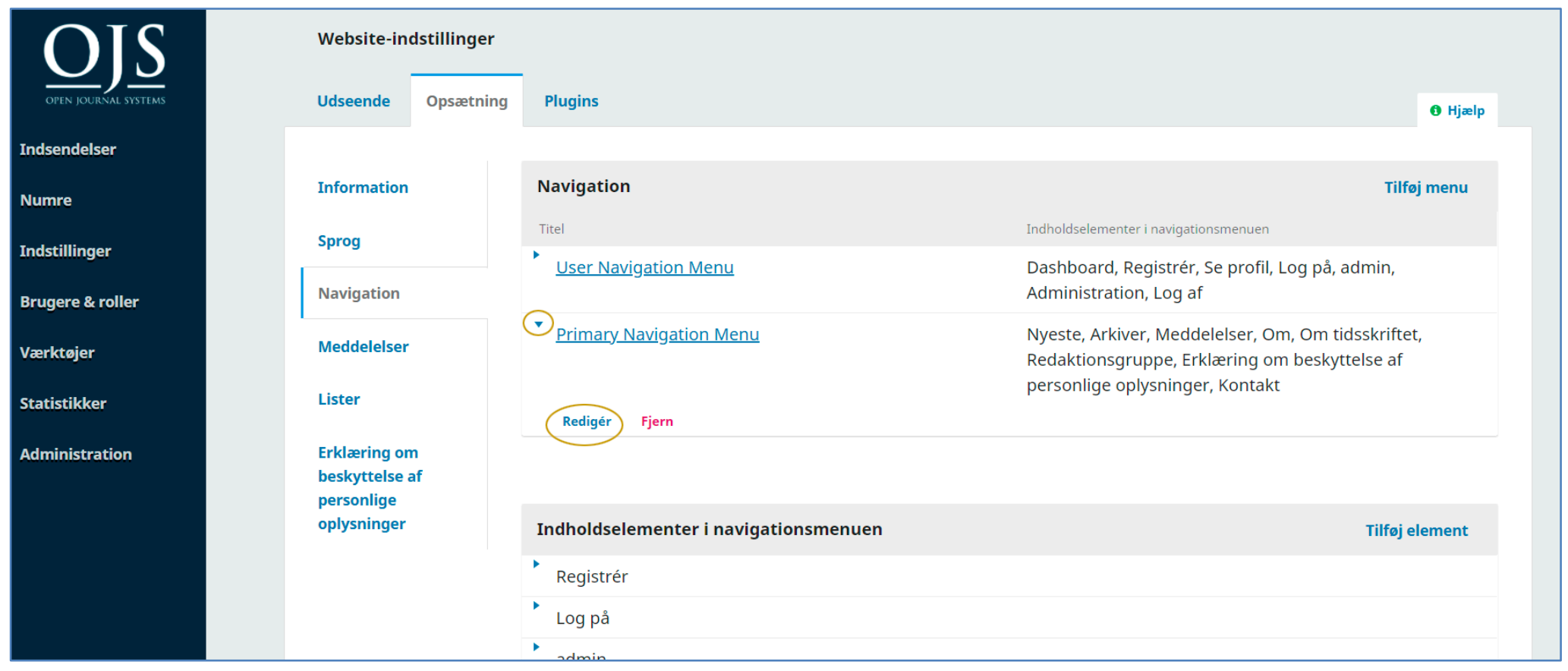


Placér nu curseren over

menuelementet 'Retningslinjer for

forfattere' og før det over i kolonnen

'Tildelte menuelementer' under 'Om'

Titel *

Primary Navigation Menu

Aktive tema-navigationsområder

primary

Vcelg et navigationsomrảde

Tildelte menuelementer

Annulerede menuelementer

- Nyeste

- Registrér

- Arkiver

Log på

- Meddelelser

$\uparrow \quad \mathrm{m}$

$\mathbf{A}$

- $\quad$ ddmin

- Dashboard

$\Phi$

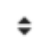

- Se profil

- Redaktionsgrupp

$\Phi$

- Administration

- Erklæring om beskyttelse af personlige oplysninger

- Log af

Kontaktperson

- $5 ø g$

- Indsendelser

- Retningslinjer for forfattere 
Når elementet er placeret som ønsket, klikkes på knappen 'Gem' nederst på siden (ikke med på billedet)
Redigér

Titel *

Primary Navigation Menu

Aktive tema-navigationsområder

primary

$\checkmark$

veelg et navigationsområde

Tildelte menuelemente

nnulerede menuelemente

$\hat{*} \quad$ Nyeste

- Arkiver

- Meddelelser

$\hat{-}$ Om

$\mathbf{\Delta}$

- Om tidsskriftet

( ) क

- Redaktionsgruppe

क)

- Retningslinjer for forfattere

Erklæring om beskyttelse af personlige oplysninger

- Kontaktperson

\$)
- Registér (D)

The pastrer

- Log på

- $\quad$ admin

- Dashboard

- Se profil

Ir Admistration

Administration

$\uparrow \quad$ Log af

$\rightarrow \quad 5 ø g$

- Indsendelser
- Kontaktperson 


\section{Herefter optræder linket til siden under menupunktet 'Om'}

\section{Nyeste Arkiver Om -}

\begin{tabular}{|l|l|l} 
Nyeste numm & Om tidsskriftet \\
Aarg. 1 Nr. 1 (2018) & $\begin{array}{l}\text { Redaktionsgruppe } \\
\text { Erklæring om beskyttelse af } \\
\text { personlige oplysninger }\end{array}$ \\
Publiceret: 2018-0! & Kontaktperson \\
\hline
\end{tabular}

4. Til sidst skal du gå ind under de enkelte sektioner.

Gå via 'Indstillinger' > 'Tidsskrift' > 'Sektioner'. Klik på den lille trekant ud for den enkelte sektion og vælg linket 'Redigér'

\begin{tabular}{|c|c|c|c|c|c|}
\hline \multicolumn{6}{|l|}{ Tidsskriftskonfiguration } \\
\hline Kolofon Kontaktperson & Sektioner & Kategorier & & & (3) $\mathrm{Hjælp}$ \\
\hline Sektioner & & & & Rækkefølge & Opret sektion \\
\hline Titel & & & Redaktører & & \\
\hline Forord & & & Ingen & & \\
\hline$\odot_{\text {Artikler }}$ & & & Ingen & & \\
\hline Redigér Slet & & & & & \\
\hline Diverse & & & Ingen & & \\
\hline
\end{tabular}


I vinduet, der kommer frem, sætter du et flueben ud for sætningen 'Elementer kan kun fremsendes af redaktører og sektionsredaktører'. Dette skal gøres ved alle tidsskriftets sektionstyper.

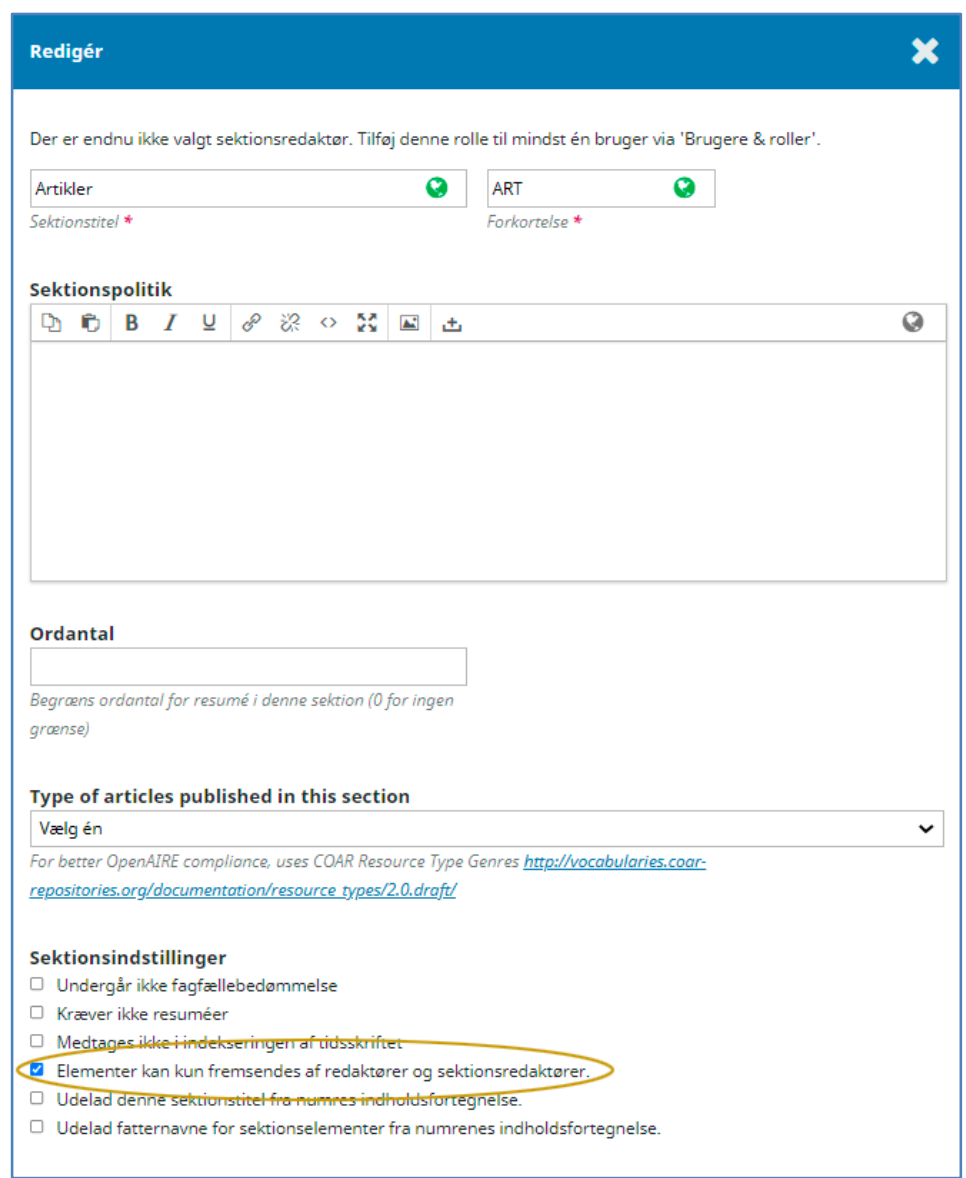

Nu er det kun redaktører og sektionsredaktører, der kan fremsende manuskripter til tidsskriftet.

' Denne vejledning er en opdatering af vejledningen Hvordan forhindrer jeg brugere i at foretage indsendelser til tidsskriftet? https://tidsskrift.dk/ojssb/article/view/116317 i Årg. 10 Nr. 9 (2019) 